Christian, J. H. B. \& Ingram, M. (1959). J. gen. Microbiol. 20, 27-31

\title{
The Freezing Points of Bacterial Cells in Relation to Halophilism
}

\author{
BY J. H. B. CHRISTIAN* AND M. INGRAM \\ Lote Temperature Station for Research in Biochemistry and Biophysics. \\ University of Cambridge and Department of Scientific and Industrial Research
}

SUMMARY: The hypothesis that halophilic bacteria achieve a high degree of salt tolerance by exclusion of much of the external solutes of the growth medium has been tested. Organisms were grown in media containing from 1 to $4 \mathrm{~m}$ salts. For both halophilic and non-halophilic bacteria the freezing points of the cells were close to those of the media in which they were grown. It is concluded that halophilic bacteria do not maintain the intracellular aqueous phase at a water activity greater than in the surrounding growth medium.

One possible explanation for the phenomenon of bacterial halophilism is that the solutes in the aqueous phase within halophilic cells are much less concentrated than in the surrounding medium (Robinson, Gibbons \& Thatcher, 1952). Such a system might be maintained, apart from mechanisms of accumulation and excretion, by a membrane impermeable to external solutes and a rigid cell boundary which resists plasmolysis. To examine this hypothesis, the freezing-point depressions of bacterial suspensions and of their growth media have been determined and compared. The bacteria included both halophilic and non-halophilic strains grown in media containing various concentrations of salts. No appreciable differences in the osmotic status of these two types of bacteria were observed.

\section{METHODS}

The four halophilic strains tested were Micrococcus halodenitrificans, Vibrio costicolus, Halobacterium halobium and Sarcina littoralis from the collection of Dr N. E. Gibbons, National Research Council, Ottowa. Other cultures used were Micrococcus lysodeikticus (NCTC 2665), Staphylococcus aureus, Escherichia coli and a salt-tolerant Bacillus circulans from the collection of the Low Temperature Research Station, Cambridge.

The red halophiles (Halobacterium halobium and Sarcina littoralis) were grown on the medium of Baxter \& Gibbons (1954), but with $2 \mathrm{M}-\mathrm{NaCl}$ and $2 \mathrm{M}-\mathrm{KCl}$. For all other bacteria the growth medium contained $0.5 \%(\mathrm{w} / \mathrm{v})$ each of proteose peptone (Difco) and tryptone (Difco) with additions of $\mathrm{NaCl}$, or of $\mathrm{NaCl}$ and $\mathrm{KCl}$ as required. The initial $\mathrm{pH}$ value was $7 \cdot 0$ in all media. These media were solidified by $2 \%(\mathrm{w} / \mathrm{v})$ Bacto agar.

To decrease the amount of contaminating medium in suspensions of organisms, the bacteria were grown on solid media in Petri dishes. An inoculum

* Present address : Division of Food Preservation and Transport, Commonwealth Scientific and Industrial Research Organization, Homebush, N.S.W., Australia. 
of $0.1 \mathrm{ml}$. was spread evenly over the surface. The plates were dried at the temperature of subsequent incubation until no free liquid remained on the surface. They were incubated inverted and without lids in sealed desiccators over salt solutions isotonic with the growth medium. The incubation temperature was $37^{\circ}$ for red halophiles and $30^{\circ}$ for other strains. The incubation period varied with the organism and with the concentration of salts.

The organisms so produced were carefully scraped from the medium by means of a thick wire and rapidly transferred to a tapered glass centrifuge tube, which was stoppered between transfers to limit evaporation. After weighing, the stoppered tube and its contents were autoclaved to break down the cell permeability barriers and any water lost was replaced from a fine capillary pipette. The wet weight of the samples ranged from 0.35 to $1.7 \mathrm{~g}$.

Freezing points were determined with a copper-constantan thermocouple, and the temperature read directly from a Pye Scalamp galvanometer calibrated in degrees Centigrade. The tip of the thermocouple was wound into a tight spiral with the junction bent inwards, so that when inserted into the cell debris the junction was centrally situated away from the wall of the tube. The thermocouple leads were held in position by a cork stopper. In most experiments the freezing mixture was $\mathrm{NaCl}+\mathrm{ice}$, but for determinations with the red halophiles $\mathrm{CaCl}_{2}+$ ice mixtures were necessary to give initial temperatures near $-30^{\circ}$.

\section{RESULTS}

The initial freezing of the sample at a cooling rate of about $2^{\circ} / \mathrm{min}$. involved substantial supercooling and the resulting freezing point was spuriously low. It was plainly essential to avoid such error. Accordingly, the sample was thawed and replaced in a freezing-mixture which gave a lower rate of freezing, so that subsequent supercooling was less and the freezing-point determination more accurate; this procedure was repeated, until the freezing point became constant. Values thus determined both during freezing and subsequent thawing never differed by more than $0 \cdot 1^{\circ}$, indicating that supercooling was not occurring.

Because, as mentioned above, it was frequently necessary to restore water lost from the pellet of cells during the previous heat treatment, freezing points were recorded with the thermocouple in three different positions. When the three values differed by more than $0 \cdot 1^{\circ}$, it was concluded that the solutes were imperfectly distributed in the aqueous phase, so the preparation was stirred with the thermocouple, and the observations repeated. The quoted values are the averages of the last three determinations.

Freezing points were similarly determined for all media before addition of agar and for all equilibrating salt solutions after growth. These two values agreed closely. Scott (1953) stated that the effect of the usual concentrations of agar on the water activity of a medium is very small.

The relationship between the freezing points of heated cell preparations and freezing points of the growth media are shown in Fig. 1, where the points refer to media with aggregate salt concentrations of 1,2 or $4 \mathrm{M}$. For a given growth 
medium the values obtained with non-halophilic bacteria were generally slightly lower than those found for the moderate halophiles. However, within both groups the differences between species were too large for any significance to be attached to this observation. There were no differences between organisms grown on media containing additions of $\mathrm{NaCl}$ and $\mathrm{KCl}$ or $\mathrm{NaCl}$ alone.

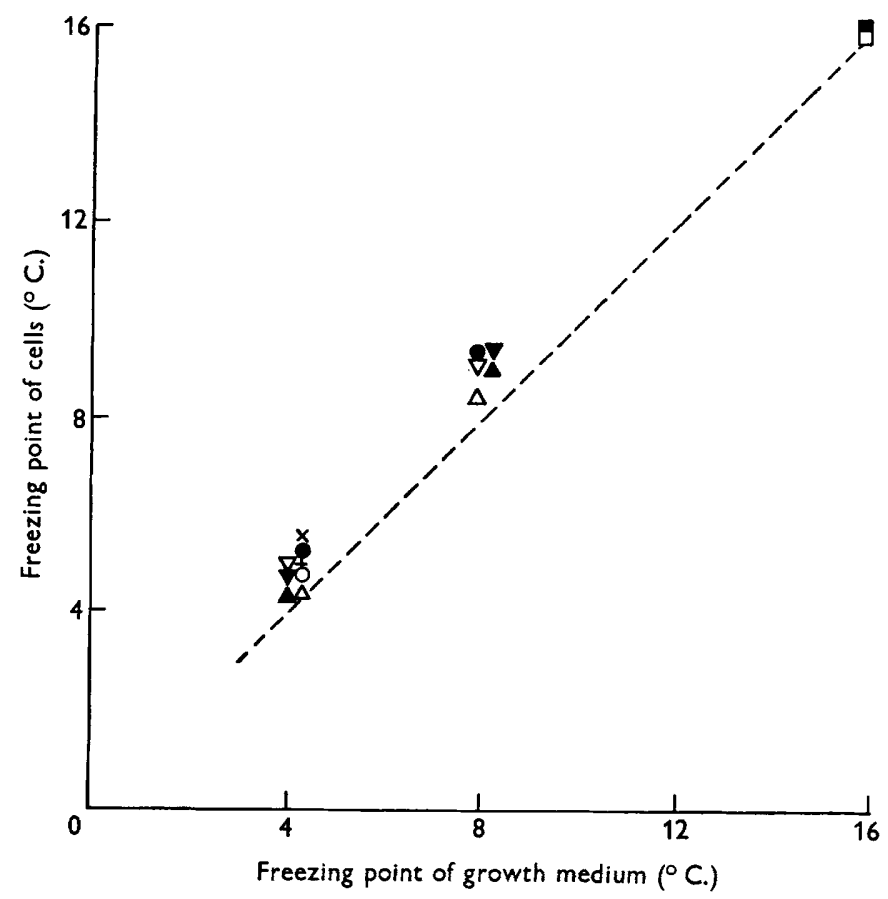

Fig. 1. Relationship between freezing points of heated organisms and growth medium. The broken line is isothermal. From media containing added $\mathrm{NaCl}$ only: $\Delta$, Micrococcus halodenitrificans; $\nabla$, Vibrio costicolus. From media containing equimolar additions of $\mathrm{NaCl}$ and $\mathrm{KCl}: \times$, Staphylococcus aureus; $\triangle$, Micrococcus halodenitrificans;,+ Escherichia coli; $\nabla$, Vibrio costicolus; $\bigcirc$, Micrococcus lysodeikticus; $\square$, Halobacterium halobium; O, Bacillus circulans; $\mathbf{\square}$, Sarcina littoralis.

The amount of contaminating growth medium contributing to the freezing point of the samples is not known. However, since the freezing points of all organisms except Halobacterium halobium were lower than those of their growth medium, corrections for contamination would increase this deficit. Hence, the freezing points of the halophilic and non-halophilic organisms were equal to or lower than the freezing points of the media on which they were grown.

\section{DISCUSSION}

The use of cryoscopic data to determine the internal osmotic status of cells is open to criticism. A major objection is that in disrupting the cells considerable changes may occur in the distribution and association of intracellular substances. Thus constituents which are normally combined in an osmotically inactive form might be liberated and large complexes broken down to smaller, 
more osmotically active units. This criticism is largely answered by the data of Mitchell \& Moyle (1956) and of Scott (1953). Mitchell \& Moyle estimated the osmotic pressure within Staphylococcus aureus by two independent methods. By equilibrating washed organisms over sucrose solutions of known concentration they deduced an osmotic pressure of 20-25 atmospheres. From the weight of solutes extracted by trichloroacetic acid from organisms of known water content they calculated a value of 20-30 atmospheres. Scott obtained similar results by the cryoscopic method. From the freezing-point depression of unwashed, centrifuged and heated $S$. aureus an osmotic pressure of about 25 atmospheres was obtained after allowing for the contribution of contaminating growth medium.

The results in Fig. 1 show that in no case was the internal aqueous content of the halophilic or non-halophilic bacteria tested likely to be less concentrated than the growth medium. Hence, it is concluded that halophilic bacteria do not owe their salt tolerant properties to an ability to maintain a comparatively low internal solute concentration.

It is further interesting that no difference appeared in pattern of behaviour between the less extreme halophiles like Micrococcus halodenitrificans and the most extreme red types like Sarcina littoralis or Halobacterium halobium. Gibbons \& Baxter (1953) concluded that the internal concentration of sodium chloride in Micrococcus halodenitrificans remained at $5 \%$ in organisms grown in concentrations ranging from 8 to $22 \%$, whereas the concentration in Sarcina littoralis increased linearly from 10 to $19 \%$ with increase of external concentration from 18 to $27 \%$. This encouraged Baxter \& Gibbons (1954) to suggest that the group of organisms typified by Micrococcus halodenitrificans possesses a special mechanism, absent from the red group, for maintaining the intracellular concentration well below that of the environment. The apparent implication would be that, with organisms grown in about $4 \mathrm{M}-\mathrm{NaCl}$, their freezing point should be about $-5^{\circ}$ for $M$. halodenitrificans but about $-10^{\circ}$, roughly twice as great, for Sarcina littoralis. Our experiments, besides indicating freezing points lower than the above values, give no hint of any such difference in behaviour between the two groups of organisms. Because the conclusion of Gibbons \& Baxter was based on estimations of chloride, however, the differences might well be due to the existence of additional solutes not accounted for by means of chloride estimations.

The nature and contribution of all the internal solutes is not known but Ingram (1938), and Yamada \& Shiio (1953), indicated that there is substantial excess of $\mathrm{Na}^{+}$over $\mathrm{Cl}^{-}$; and Christian (1956) found that halophilic organisms contained large amounts of potassium as well as sodium, the former probably predominating in the red extreme halophiles. Thus it is suggested that the salts of both these cations are largely responsible for the low internal water activities indicated by freezing-point determinations.

For a given strain grown in widely differing concentrations of salts there was a fairly constant difference between the freezing points of the cell contents and the growth medium. It has also been shown (Christian \& Ingram, 1959) that the osmotic sensitivity of both halophilic and non-halophilic 
bacteria is proportional to the $\mathrm{NaCl}$ content of the medium during growth. From these data it is concluded that the osmotic status of bacterial cells is very largely determined by the water activity of the growth medium.

This work was carried out as part of the programme of the Food Investigation Organization of the Department of Scientific and Industrial Research during the tenure by one of us (J.H.B.S.) of an Overseas Studentship of the Commonwealth Scientific and Industrial Research Organization.

\section{REFERENCES}

Baxter, R. M. \& Gibbons, N. E. (1954). The glycerol dehydrogenases of Pseudomonas salinaria, Vibrio costicolus and Escherichia coli in relation to bacterial halophilism. Canad. J. Biochem. Physiol. 32, 206.

Christian, J. H. B. (1956). The physiological basis of salt tolerance in halophilic bacteria. Dissertation, Cambridge.

Christian, J. H. B. \& Ingram, M. (1959). Lysis of Vibrio costicolus by osmotic shock. J. gen. Microbiol. $20,32$.

Gibbons, N. E. \& Baxter, R. M. (1953). The relation between salt concentration and enzyme activity in halophilic bacteria. Proc. VIth int. Congr. Microbiol., Rome, 1, 210.

INGRAM, M. (1938). The effect of sodium chloride on a bacterial enzyme which destroys lactic acid. Rep. Fd Invest. Bd Lond., p. 72.

Mitchell, P. \& Moyle, J. (1956). Osmotic structure and function in bacteria. In Bacterial Anatomy. Symp. Soc. gen. Microbiol. 6, 150.

Robinson, J., Gibbons, N. E. \& Thatcher, F. S. (1952). A mechanism of halophilism in Micrococcus halodenitrificans. J. Bact. 64, 69.

Scort, W. J. (1953). Water relations of Staphylococcus aureus at $30^{\circ}$ C. Aust. J. biol. Sci. 6, 549.

YAMADA, T. \& SHIro, I. (1953). Effects of salt concentration on the respiration of a halotolerant bacterium. J. Biochem., Tokyo, 40, 327.

(Received 24 June 1958) 